\title{
Development of Flow Injection Spectrophotometric Method for 1-Napthylthiourea Using Sodium Nitrite and Sulphanilic Acid Diazotization Reaction
}

\author{
Muhammad Asghar, ${ }^{1}$ Mohammad Yaqoob (iD, ${ }^{1}$ Sami Ullah,, ${ }^{1}$ Samar Ali, ${ }^{1}$ Nusrat Munawar, ${ }^{2}$ \\ and Abdul Nabi ${ }^{1}$ \\ ${ }^{1}$ Department of Chemistry, University of Balochistan, Quetta 87300, Pakistan \\ ${ }^{2}$ Department of Chemistry, Sardar Bahadur Khan Women's University, Quetta, Pakistan
}

Correspondence should be addressed to Mohammad Yaqoob; yaqoob2001@hotmail.com

Received 20 January 2018; Accepted 12 April 2018; Published 8 May 2018

Academic Editor: Rizwan Hasan Khan

Copyright (c) 2018 Muhammad Asghar et al. This is an open access article distributed under the Creative Commons Attribution License, which permits unrestricted use, distribution, and reproduction in any medium, provided the original work is properly cited.

\begin{abstract}
A simple spectrophotometric method in conjunction with flow injection analysis is developed for the quantitative analysis of 1napthylthiourea (ANTU). The reaction is based on the alkaline hydrolysis of ANTU to 1-naphthylamine at $30^{\circ} \mathrm{C}$, coupled with diazotized sulphanilic acid resulting in 4-(sulphophenylazo)-1-naphthylamine which is monitored at $495 \mathrm{~nm}$. The limit of detection $(S / N=3)$ is $0.01 \mathrm{mg} / \mathrm{L}$ with a sampling throughput of $45 / \mathrm{h}$. The method is linear over the range of $0.05-120 \mathrm{mg} / \mathrm{L}$ $\left(R^{2}=0.9995, n=7\right)$, with calibration equation $y=0.031 x-0.018(y=$ absorbance; $x=\mathrm{mg} / \mathrm{L})$ and relative standard deviation $(n=3)$ $1.8-3.6 \%$. Experimental variables are optimised, and the interfering effects of different pesticides, organic compounds, cations, and anions at environmentally relevant concentrations are investigated. The analysis of ANTU in spiked water samples is extracted with solid phase procedure using disposable Sep-Pak C18 cartridges, and the recovery was $93 \pm 1.9-110 \pm 3.0 \%$. The results of the proposed method are compared with the HPLC method by applying the $F$-test and paired Student $t$-test at $95 \%$ confidence level.
\end{abstract}

\section{Introduction}

1-Napthylthiourea (ANTU) is a rodenticide that belongs to the class of organosulfur pesticide and available in the form of white crystalline powder [1-4]. It is used as $10 \%$ active baits or $20 \%$ tracking powder [5]. It is specifically used to control adult Rattus norveqicus, and $6-8 \mathrm{mg} / \mathrm{kg}$ is sufficient as a toxic dose; however, other species of Rattus are less toxic to it. The repetitive administration of rates with its sublethal doses develops tolerance [6]. In general, domestic animals are safe from its toxic effects, but the induction of vomiting in dogs and production of pleural effusion and pulmonary oedema in other experimental animals have been reported [7].

Human exposure to ANTU could be through ingestion, inhalation, or skin contact with the recommended occupational airborne exposure over an average of a ten-hour work shift is $0.3 \mathrm{mg} / \mathrm{m}^{3}$, while an exposure of $100 \mathrm{mg} / \mathrm{m}^{3}$ has been reported to be dangerous for human health [3]. A $4000 \mathrm{mg}$.ANTU/kg human body weight has been assigned as a lethal dose [8]. It does not degrade in the presence of sunlight and air. 1-naphthylamine can cause coughing, breath shortness, or fluid buildup in the lungs. It is the main degraded product of ANTU and is considered to be a first-class carcinogen, which can easily enter the fluvial systems in different ways $[8,9]$. The chemical structure of ANTU is shown in Figure 1.

Various analytical procedures have been employed for the determination of ANTU in biological, food, and environmental samples. These include colorimetry [10, 11], fluorimetry [12], voltammetry $[13,14]$, liquid chromatography based on different detectors [15-18], and stop flow injection chemiluminescence [19]. They are accurate and sensitive, however, require large amount of reagents, lengthy procedures, low sample throughputs, and expertise. Spectrophotometry continues to gain popularity due to simplicity, speed, precision, 
<smiles>NC(=S)Nc1cccc2ccccc12</smiles>

FIGURE 1: Chemical structure of ANTU ( $\alpha$-naphthylthiourea).

accuracy, and availability of instrumentation. The flow injection analysis (FIA) is well established for the analysis of diverse analytes in the environmental, clinical, food, and other areas. It has the advantages of high injections throughput, low sample and reagent consumption, and high versatility and robustness. In particular, spectrophotometry has become the most widely used detection technique in FIA [20].

This study reports a simple FI spectrophotometric method for the determination of ANTU in natural waters, based on the conversion of nitrite into nitrous acid, subsequent diazotization of sulphanilic acid, and formation of the diazonium salt. The diazonium salt is coupled with 1-naphthylamine, the hydrolysed product of ANTU under alkaline conditions to form 4-(sulphophenylazo)-1-naphthylamine $[9,21]$. The azo dye formed is monitored at $495 \mathrm{~nm}$. The interfering effects of different pesticides, organic compounds, cations, and anions have also been investigated. ANTU from water samples has been extracted using a solid phase extraction technique, analysed by the proposed method, and validated by the HPLC method.

\section{Experimental}

2.1. Materials and Solutions. All chemicals used were of analytical grade provided by Merck (Darmstadt, Germany) and BDH Chemicals Ltd. (Poole, UK). Glassware and bottles were precleaned in $10 \%$ hydrochloric acid for three days, thoroughly rinsed with deionised water $(0.067 \mu \mathrm{S} / \mathrm{cm}$, Elga Purelab Option, High Wycombe, Bucks, UK) and stored in the zip-locked plastic bags. A $0.1 \mathrm{M}$ stock solution of sulphanilic acid was freshly prepared by dissolving $4.33 \mathrm{~g}$ in deionised water, sonicated for $5 \mathrm{~min}$, diluted to $250 \mathrm{~mL}$ with deionised water, and stored in a dark brown bottle. A $0.25 \mathrm{M}$ stock solution of sodium nitrite was prepared by dissolving $4.3 \mathrm{~g}$ in deionised water, and the volume was made up to $250 \mathrm{~mL}$ with deionised water. A $2.0 \mathrm{M}$ stock solution of sodium hydroxide was prepared by dissolving $8.0 \mathrm{~g}$ in deionised water, and the volume was made up to $100 \mathrm{~mL}$ with deionised water. Working standard solutions were prepared from these stock solutions in deionised water when required. Commercially available absolute ethanol was used for making different ethanol working standard solutions $(\% \mathrm{v} / \mathrm{v})$ with deionised water.

For the preparation of $250 \mathrm{mg} / \mathrm{L}$ stock solutions of ANTU, asulam, diazinon, malathion, maneb, nabam, phoxim, terbufos, thiabendazole, and thiram (Dr. Ehrenstorfer, Augsburg, Germany), the preweighed amounts of these pesticides were dissolved in absolute ethanol. All these solutions were sonicated and stored in dark brown bottles at $4^{\circ} \mathrm{C}$ when not in use. These solutions were diluted serially to obtain lower concentrations using $0.25 \%(\mathrm{v} / \mathrm{v})$ ethanol solution containing $75 \mathrm{mM}$ sodium hydroxide.

For the preparation of $2000 \mathrm{mg} / \mathrm{L}$ stock solutions of cations, such as sodium, potassium, magnesium, calcium, iron, manganese, and cobalt, and anions, such as chloride, nitrate, sulphate, and phosphate, the required quantities of related salts were dissolved in deionised water and the working standard solutions were prepared in $0.25 \%$ ethanol solution containing $75 \mathrm{mM}$ sodium hydroxide.

2.2. Flow Injection Manifold. The proposed three-channel FI manifold is shown in Figure 2. All the streams were propelled at a flow rate of $0.5 \mathrm{~mL} / \mathrm{min}$ by using a 4 -channel peristaltic pump (Reglo 100, Glattbrugg-Zurich, Switzerland). The standards and samples of ANTU $(300 \mu \mathrm{L})$ were injected via a rotary injection valve (Rheodyne 5020, Anachem, Luton, UK) into the carrier stream of $0.25 \%(\mathrm{v} / \mathrm{v})$ ethanol solution containing $75 \mathrm{mM}$ sodium hydroxide, which resulted in the formation of 1-naphthaylamine. For diazonium salt formation, the streams of $100 \mathrm{mM}$ sulphanilic acid and $50 \mathrm{mM}$ sodium nitrite were merged at a T-piece and allowed to pass through a $200 \mathrm{~cm}$ reaction coil-I, thermostated at $30^{\circ} \mathrm{C}$. This stream was then merged with the carrier stream containing 1-naphthylamine at a confluence point and passed through $150 \mathrm{~cm}$ reaction coil-II which was also thermostated at $30^{\circ} \mathrm{C}$. This resulted in the formation of 4-(sulphophenylazo)-1naphthylamine monitored at $495 \mathrm{~nm}$ using a UV-Vis spectrophotometer (Model 6505, Jenway Ltd., Feisted, Dunmow, Essex, UK) and equipped with a quartz flowthrough cell (path length $1 \mathrm{~cm}$, volume $80 \mu \mathrm{L}$, Hellma Analytics, Germany). The absorbance was recorded on a chart recorder (BD40, Kipp \& Zonen, Delft, Netherlands). Polytetrafluoroethylene tubes $(0.8 \mathrm{~mm}$ i.d., Fisher Scientific, Loughborough, UK) were used to join all connections of FIA manifold.

2.3. Water Samples Collection. Natural water samples such as tap, irrigation, and lake water from Quetta valley were collected in $10 \%$ hydrochloric acid, washed in high-density polyethylene bottles, and stored in the dark at $4^{\circ} \mathrm{C}$. For the removal of suspended solids, water samples were filtered through a cellulose membrane filter (diameter $47 \mathrm{~mm}$; pore size $0.45 \mathrm{~mm}$ ), (Whatman, Madistone, UK), stored at $4^{\circ} \mathrm{C}$, and analysed when required.

The water samples were spiked with ANTU in the range from 0.5 to $3.0 \mathrm{mg} / \mathrm{L}$ and extracted with solid phase extraction (SPE) using disposable Sep-Pak C18 cartridges (Water Associates, USA). The cartridge was first conditioned with $5.0 \mathrm{~mL}$ deionised water, $5 \mathrm{~mL}$ ethanol, and then dried by passing air through it for two minutes. The water sample was passed at a flow rate of $10 \mathrm{~mL} / \mathrm{min}$ through the conditioned SPE cartridge, washed with $0.5 \mathrm{~mL}$ deionised water, and dried by passing air through it for $10 \mathrm{~min}$. ANTU from the SPE cartridge was eluted with $5.0 \mathrm{~mL}$ ethanol and dried under a nitrogen stream. The dried ANTU residues were redissolved in $0.25 \%$ ethanol containing $75 \mathrm{mM}$ sodium 


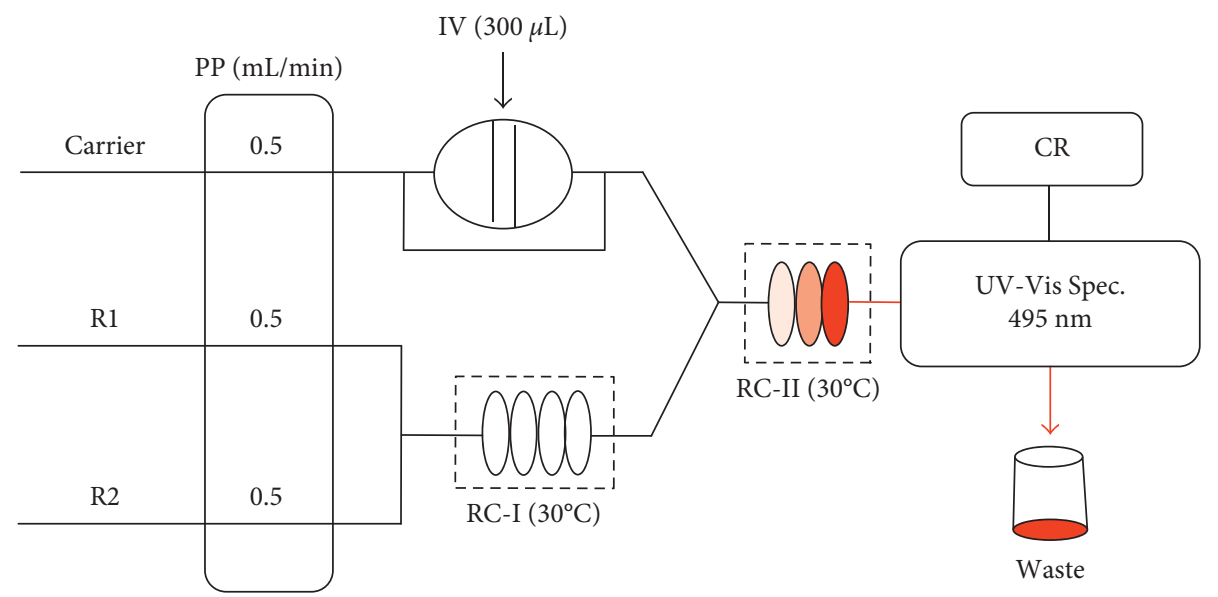

FIgURE 2: Optimised FI spectrophotometric manifold for the determination of ANTU. Carrier, 0.25\% (v/v) ethanol solution containing $75 \mathrm{mM}$ sodium hydroxide; R1, $50 \mathrm{mM}$ sodium nitrite solution; R2, $100 \mathrm{mM}$ sulphanilic acid solution; PP, peristaltic pump; IV, injection valve; RC-I, reaction coil-I, $200 \mathrm{~cm}$; RC-II, reaction coil-II, $150 \mathrm{~cm}$; CR, chart recorder.

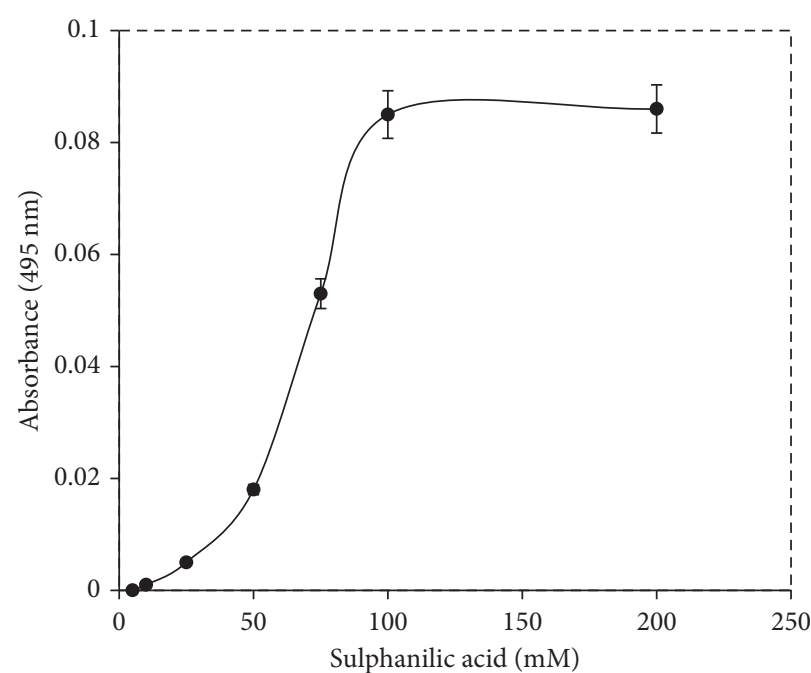

(a)

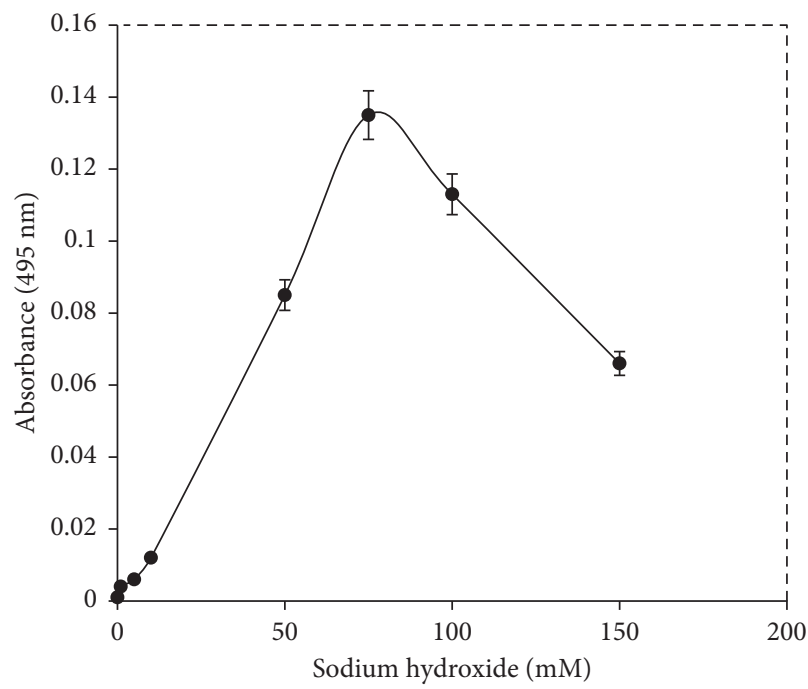

(c)

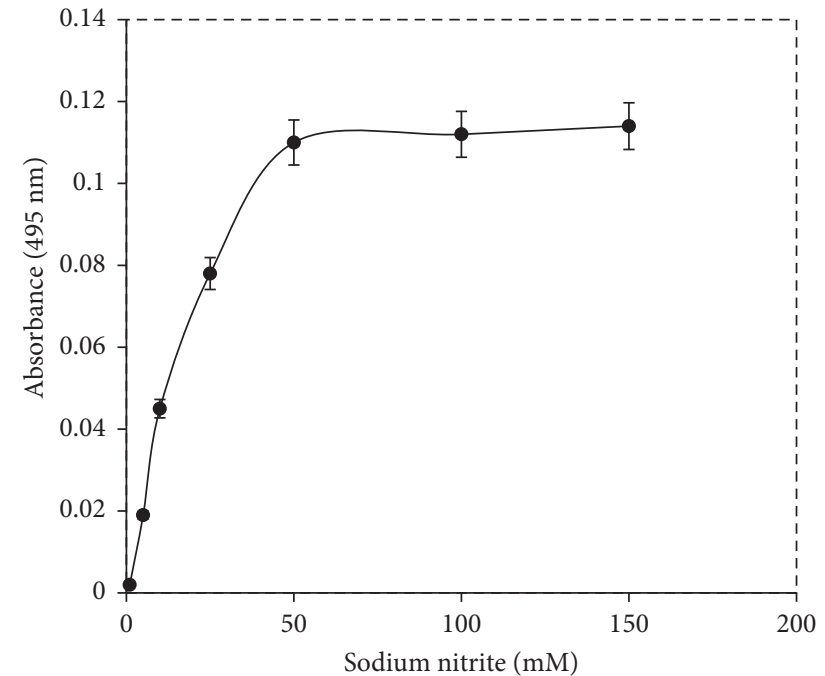

(b)

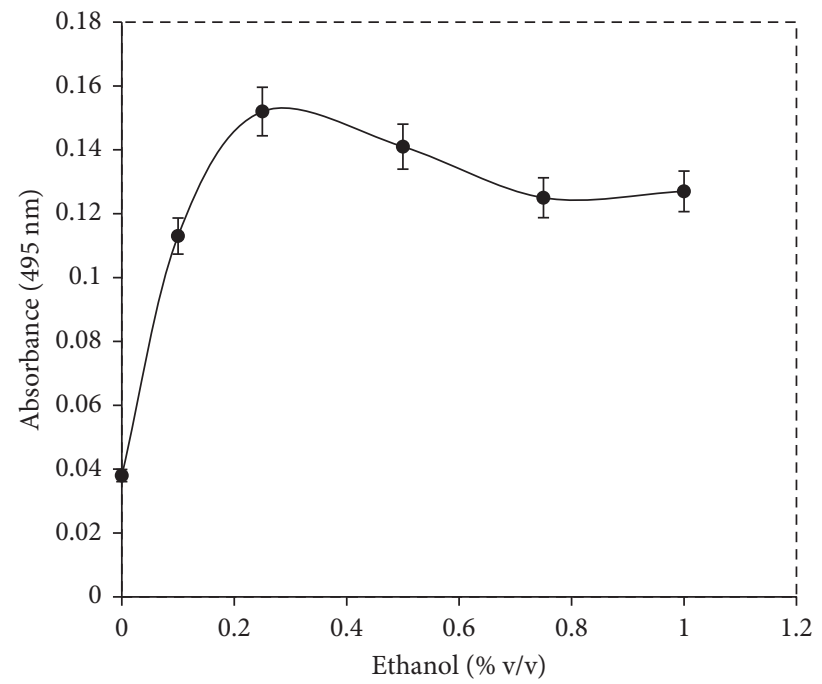

(d)

Figure 3: Optimization of reagents concentration. (a) Sulphanilic acid, (b) sodium nitrite, (c) sodium hydroxide, and (d) ethanol. Experimental conditions: flow rate $0.5 \mathrm{~mL} / \mathrm{min}$, sample loop volume $300 \mu \mathrm{L}$, reaction coil-I length $200 \mathrm{~cm}$, reaction coil-II length $150 \mathrm{~cm}$, wavelength $495 \mathrm{~nm}$, temperature $30^{\circ} \mathrm{C}$, and ANTU concentration $10 \mathrm{mg} / \mathrm{L}$. 
TABLE 1: Effect of physical variables on the determination of ANTU $(n=4)$.

\begin{tabular}{lcc}
\hline Physical variables & Range studied & Optimum \\
\hline Flow rate $(\mathrm{mL} / \mathrm{min})$ & $0.2-1.2$ & 0.5 \\
Sample injection volume $(\mu \mathrm{L})$ & $60-360$ & 300 \\
Reaction coil-I length $(\mathrm{cm})$ & $0-300$ & 200 \\
Reaction coil-II length $(\mathrm{cm})$ & $0-300$ & 150 \\
Reaction coil-I and -II & $10-50$ & 30 \\
temperature $\left({ }^{\circ} \mathrm{C}\right)$ & & \\
\hline
\end{tabular}

hydroxide and $0.1 \%$ acetic acid-acetonitrile $(55: 45, \mathrm{v} / \mathrm{v})$, and both were analysed by the proposed method and a previously reported HPLC method [15], respectively.

2.4. HPLC Method. The ANTU standards and samples were analysed by the HPLC method as reported previously [15]. In brief, a liquid chromatograph (Model LC-10AT, Shimadzu, Corporation, Tokyo, Japan) equipped with a UVVis detector (SPD-10A) set at $220 \mathrm{~nm}$ was employed. The samples were introduced through a six port injection valve (Model 7725i, Rheodyne) with a sample loop volume of $10 \mu \mathrm{L}$. The chromatographic analysis was performed on an analytical column (Bondapak C18: $250 \times 4.6 \mathrm{~mm}$ i.d., $10 \mu \mathrm{m}$ ) using $0.1 \%$ acetic acid-acetonitrile $(55: 45, \mathrm{v} / \mathrm{v})$ as a mobile phase at a flow rate of $2 \mathrm{~mL} / \mathrm{min}$. Under these conditions, the retention time for ANTU was $2.1 \mathrm{~min}$ while a linear calibration graph was obtained by injecting the analyte standard solutions over the range $0.1-5 \mathrm{mg} / \mathrm{L}$. The residues of analyte after SPE were dissolved in the mobile phase and analysed by the method.

\section{Results and Discussion}

3.1. Experimental Results. Various analytical parameters were optimised to enhance the sensitivity, increase the dynamic linear range and sample throughput, and reduce reagents consumption. All these studies were performed with $10 \mathrm{mg} / \mathrm{L}$ ANTU standard solution.

The spectrum of the final product of the reaction (Scheme 3) under the optimum conditions was scanned from 200 to $600 \mathrm{~nm}$. The maximum absorption wavelength of $495 \mathrm{~nm}$ was selected as an optimum wavelength for subsequent experiments in the flow mode.

The effect of sulphanilic acid concentration in the range of $0.5-200 \mathrm{mM}$ was examined. At $0.5 \mathrm{mM}$ concentration, no absorbance was observed; however, when the sulphanilic acid concentration was increased, the absorbance increased linearly. The maximum absorbance was observed at $100 \mathrm{mM}$ sulphanilic acid concentration as shown in Figure 3(a). Beyond this concentration, the absorbance remained constant, and bubbles were observed in reaction coil-II due to nitrogen gas generation as a result of the degradation of the diazonium ion. Moreover, the maximum solubility of sulphanilic acid concentration $(85 \mathrm{mM})$ at $30^{\circ} \mathrm{C}$ was reported [22]. Therefore, the optimum sulphanilic acid concentration of $100 \mathrm{mM}$ was selected and used for subsequent studies.

Sodium nitrite was used to generate nitrous acid in acidic medium, and its effect was examined in the concentration

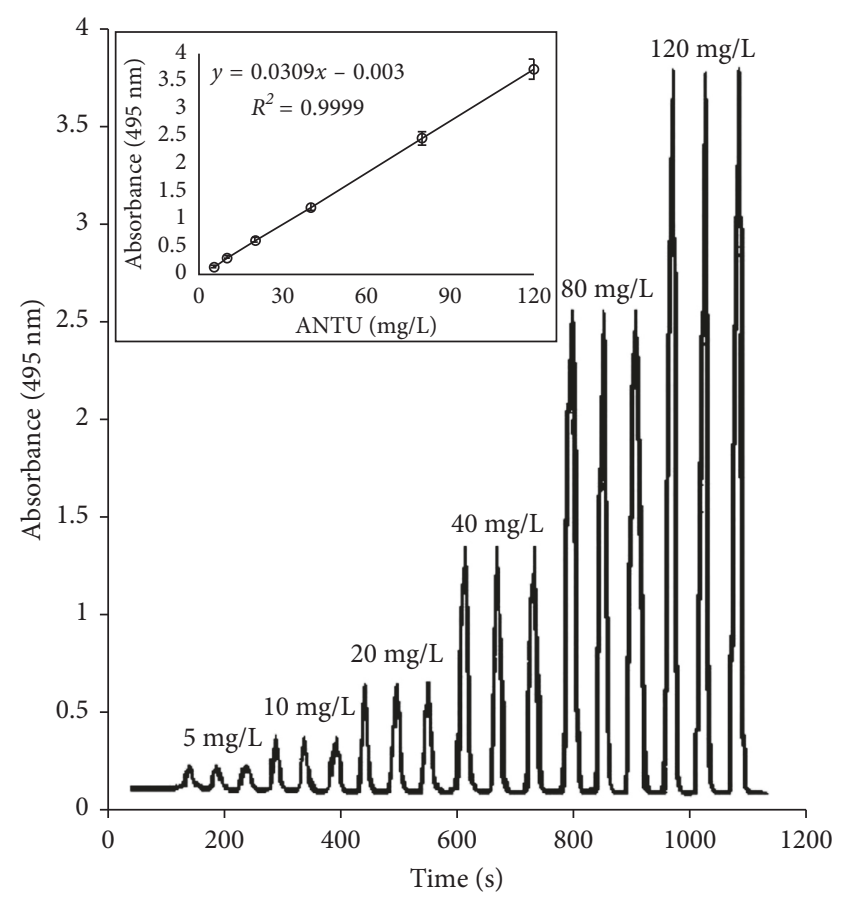

FIgURE 4: Traces of absorbance peak height for a series of ANTU standards injected in triplicate (inset shows the calibration curve).

range of 1-150 mM. Maximum absorbance was obtained at $50 \mathrm{mM}$ as shown in Figure 3(b). Further increase in the sodium nitrite concentration had shown no appreciable increase in the absorbance; therefore, sodium nitrite concentration of $50 \mathrm{mM}$ was selected and used for further studies.

Sodium hydroxide was used to hydrolyse ANTU into 1naphthylamine [12] and also as a reaction medium for the proposed chemistry. The effect of sodium hydroxide concentration in the range 1-150 $\mathrm{mM}$ was examined. Maximum absorbance was observed at $75 \mathrm{mM}$; above which, the absorbance was decreased as shown in Figure 3(c). Therefore, the sodium hydroxide concentration of $75 \mathrm{mM}$ with a waste (combined stream) of $\mathrm{pH} 10$ was chosen for further studies.

The solubility of ANTU in water has been reported as about $600 \mathrm{mg} / \mathrm{L}$, while in organic solvents, it has the solubility of, for example, 24300 and $86000 \mathrm{mg} / \mathrm{L}$ in acetone and triethyleneglycol, respectively [2]. Hence, the effect of ethanol in the range $0-1 \%(\mathrm{v} / \mathrm{v})$ was examined as a sample carrier stream. The absorbance was increased with an increase in ethanol concentration up to $0.25 \%$ above which the peak height absorbance was decreased as shown in Figure 3(d). Therefore, ethanol concentration of $0.25 \%$ was selected and used as a sample carrier stream.

To achieve high sensitivity, linear calibration range, and economy of reagents consumption, the effects of various physical parameters such as reagent streams flow rates, sample loop volume, reaction coil lengths, and temperature were examined (Table 1 ). The effect of flow rates for each of the three streams in the range $0.2-1.2 \mathrm{~mL} / \mathrm{min}$ was examined simultaneously. Maximum absorbance was observed at $0.5 \mathrm{~mL} / \mathrm{min}$ with a steady baseline and reproducible peak height; 
TABLE 2: Comparison of analytical characteristics of the proposed method with other methods used for the analysis of ANTU.

\begin{tabular}{|c|c|c|c|c|c|}
\hline Technique & Sample matrix & Linear range $(\mathrm{mg} / \mathrm{L})$ & LOD $(\mathrm{mg} / \mathrm{L})$ & $R^{2}$ & Reference \\
\hline $\mathrm{FL}^{\mathrm{a}}$ & Wheat grain & $0.05-1.00$ & 0.01 & 0.999 & [12] \\
\hline $\mathrm{DPP}^{\mathrm{b}}$ & Urine & $0.2-10$ & 0.04 & - & {$[13]$} \\
\hline $\mathrm{ASV}^{\mathrm{c}}$ & Cattle feed and urine & Up to 0.81 & $8 \times 10^{-5}$ & 0.9980 & {$[14]$} \\
\hline HPLC-DAD ${ }^{\mathrm{d}}$ & River water & - & $1.2 \times 10^{-3}$ & 0.9978 & {$[15]$} \\
\hline HPLC-MS & Water & $2 \times 10^{-4}-2.5 \times 10^{-2}$ & $9.57 \times 10^{-4}$ & - & {$[16]$} \\
\hline sFI-CL ${ }^{\mathrm{f}}$ & Water, wheat, barley, and oat grain & $0.05-3$ & 0.005 & 0.998 & [19] \\
\hline FI spectrophotometry & Water & $0.05-120$ & 0.01 & 0.9995 & This work \\
\hline
\end{tabular}

${ }^{a}$ Flourimetry; ${ }^{b}$ differential pulse polarography; ${ }^{c}$ adsorptive stripping voltammetry; ${ }^{\mathrm{d}}$ high-performance liquid chromatography-diode array detector; ${ }^{\mathrm{e}}$ highperformance liquid chromatography-mass spectrometry; ${ }^{\mathrm{f}}$ stop flow injection-chemiluminescence.

TABLE 3: Percent recovery of ANTU in spiked natural water samples $(n=4)$.

\begin{tabular}{|c|c|c|c|c|c|}
\hline \multirow{2}{*}{ Sample matrix } & \multirow{2}{*}{ Spiked (mg/L) } & \multicolumn{2}{|c|}{ Proposed method } & \multicolumn{2}{|c|}{ HPLC method [15] } \\
\hline & & Found $(\mathrm{mg} / \mathrm{L})$ & Recovered (\%) & Found $(\mathrm{mg} / \mathrm{L})$ & Recovered (\%) \\
\hline \multirow{4}{*}{ Tap water } & 0.50 & $0.49 \pm 0.012$ & $98 \pm 2.5$ & $0.505 \pm 0.011$ & $101 \pm 2.2$ \\
\hline & 1.00 & $0.93 \pm 0.018$ & $93 \pm 1.9$ & $1.02 \pm 0.032$ & $102 \pm 3.1$ \\
\hline & 1.50 & $1.44 \pm 0.040$ & $96 \pm 2.8$ & $1.48 \pm 0.027$ & $99 \pm 1.8$ \\
\hline & 1.00 & $1.03 \pm 0.022$ & $103 \pm 2.1$ & $1.10 \pm 0.033$ & $110 \pm 3.0$ \\
\hline \multirow{2}{*}{ Irrigation water } & 2.00 & $2.09 \pm 0.050$ & $105 \pm 2.4$ & $1.92 \pm 0.063$ & $96 \pm 3.3$ \\
\hline & 3.00 & $3.12 \pm 0.097$ & $104 \pm 3.1$ & $2.81 \pm 0.048$ & $94 \pm 1.7$ \\
\hline \multirow{3}{*}{ Lake water } & 1.00 & $0.97 \pm 0.032$ & $97 \pm 3.3$ & $1.06 \pm 0.021$ & $106 \pm 2.0$ \\
\hline & 2.00 & $2.07 \pm 0.066$ & $103.5 \pm 3.2$ & $1.96 \pm 0.031$ & $98 \pm 1.6$ \\
\hline & 3.00 & $3.21 \pm 0.051$ & $107 \pm 1.6$ & $3.13 \pm 0.10$ & $104 \pm 3.2$ \\
\hline
\end{tabular}

$t_{\text {calc. }}=0.884 ; t_{\text {tab. }, v=8, p=0.05}=2.31 ; F_{\text {calc. }}=1.262 ; F_{\text {tab. }, v 1=8, v 2=8, p=0.05}=3.44$.

therefore, the flow rate of $0.5 \mathrm{~mL} / \mathrm{min}$ was employed subsequently. The sample volume in the range $60-360 \mu \mathrm{L}$ was investigated. The absorbance increased with the increase in the sample volume up to $300 \mu \mathrm{L}$; therefore, a sample volume of $300 \mu \mathrm{L}$ was selected and subsequently used. The effect of reaction coil-I and coil-II lengths in the range $0-300 \mathrm{~cm}$ was examined on the diazotization process and formation of azo dye, respectively. The maximum peak height absorbance was obtained when the reaction coil lengths were 200 and $150 \mathrm{~cm}$ and further increase in coil lengths had little effect on absorbance. Therefore, the reaction coil-I and coil-II lengths of 200 and $150 \mathrm{~cm}$ were chosen and used for further studies, respectively.

The effect of reaction coil temperature in the range $10-50^{\circ} \mathrm{C}$ was also examined. The maximum absorbance was obtained at $30^{\circ} \mathrm{C}$, above which bubbles were observed in the reaction coils probably due to possible dissociation of diazotized sulphanilic acid into nitrogen gas. Therefore, the reaction coil temperature of $30^{\circ} \mathrm{C}$ was fixed and employed for subsequent studies.

3.2. Analytical Figures of Merit. Under the optimum conditions described above, the calibration graph of absorbance versus ANTU concentrations was linear in the range 0.05$120 \mathrm{mg} / \mathrm{L}$. The coefficient of determination $\left(R^{2}\right)$, relative standard deviation $(n=3)$, and regression equation over the range studied were $0.9995(n=7), 1.8-3.6 \%$, and $y=0.031 x-0.018$ (where $y=$ absorbance and $x=$ concentration in $\mathrm{mg} / \mathrm{L}$ ), respectively. The limit of detection (LOD) based on the concentration response that equals to three times of the peak-topeak baseline noise $(S / N=3)$ was $0.01 \mathrm{mg} / \mathrm{L}$. The injection<smiles></smiles>

SCHeme 1

throughput was $45 /$ h. Figure 4 illustrates the chart recorder traces of absorbance at $495 \mathrm{~nm}$ for the concentration range of 5-120 mg/L ANTU and a calibration curve in the inset for the same standard solutions.

Table 2 reports the comparison of the analytical characteristics of the proposed method with other methods used for the determination of ANTU. The proposed FI spectrophotometric system has satisfactory linearity, sensitivity, sample throughput, and precision.

3.3. Interferences. The influence of different cations, anions, organic compounds, and some pesticides with and without ANTU was carried out. The tolerable level of these chemical species was selected as the concentration which did not enhance or inhibit the peak height absorbance for ANTU at $0.1 \mathrm{mg} / \mathrm{L}$ by more than $5 \%$. No significant effect of $\mathrm{Na}^{+}, \mathrm{K}^{+}$, $\mathrm{Ca}^{2+}, \mathrm{Mg}^{2+}, \mathrm{Mn}^{2+}, \mathrm{Fe}^{3+}, \mathrm{Co}^{2+}, \mathrm{PO}_{4}{ }^{3-}, \mathrm{SO}_{4}{ }^{2-}, \mathrm{Cl}^{-}$, and $\mathrm{NO}_{3}{ }^{-}$ 1000-fold, phenol and humic acid 10-fold, asulam, diazinon, malathion, maneb, nabam, phoxim, terbufos, thiabendazole, and thiram 50-fold was observed. Therefore, the method 


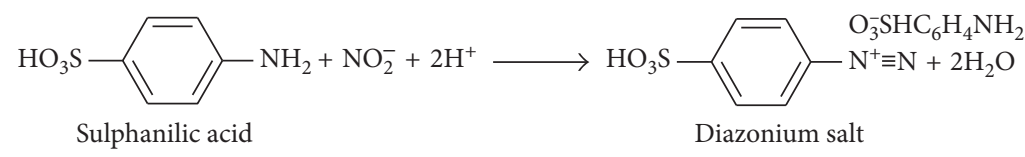

SCHEME 2

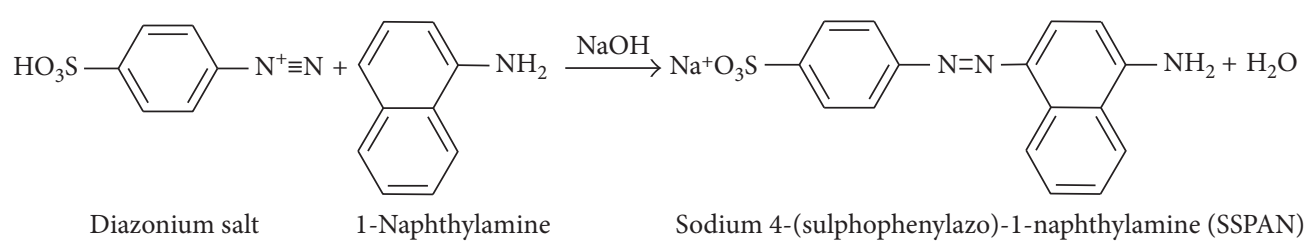

Scheme 3

could be easily applied for ANTU analysis in real samples in the presence of the above chemical species.

3.4. Application. The proposed method was successfully applied for the determination of ANTU in natural water samples. Table 3 reports the results of water samples spiked with ANTU standards which were in good agreement with the reported HPLC method [15] with recovery from $93 \pm 1.9$ to $110 \pm 3.0 \%$. There was no significant difference between the variances and mean results of the two methods at 95\% confidence level by applying the $F$ - and $t$-tests $\left(t_{\text {calc. }}=0.884, t_{\text {tab. }, v=8, p=0.05}=2.31\right.$, $\left.F_{\text {calc. }}=1.262, F_{\text {tab. }, v 1=8, v 2=8, p=0.05}=3.44\right)$.

3.5. Possible Reaction Scheme. In the alkaline medium, ANTU was hydrolysed and 1-naphthylamine was formed (Scheme 1) [12]. Nitrite was converted into nitrous acid in the acidic medium; subsequent diazotization of sulphanilic acid and formation of diazonium salt are shown in Scheme 2. This salt was then coupled with 1-naphthylamine in an alkaline medium to form sodium 4-(sulphophenylazo)-1naphthylamine salt (Scheme 3) [9, 23]. The resulting azo dye had shown maximum absorption wavelength at $495 \mathrm{~nm}$.

\section{Conclusions}

A simple FI spectrophotometric method was developed enabling the quantitation of ANTU with low LOD $(0.01 \mathrm{mg} / \mathrm{L})$ and good sample throughput $(45 / \mathrm{h})$. Anions and cations and number of pesticides had no influence on the quantitation of ANTU. The developed procedure was successfully applied for the determination of ANTU in spiked natural water samples using the SPE technique with recovery from $93 \pm 1.9$ to $110 \pm 3.0 \%$. There was no significant difference between the proposed FI spectrophotometric and HPLC method at $95 \%$ confidence interval by applying the tests of significance.

\section{Data Availability}

The data used to support the findings of this study are available from the corresponding author upon request.

\section{Conflicts of Interest}

The authors declare that there are no conflicts of interest regarding the publication of this paper.

\section{Acknowledgments}

This research work was conducted at the Department of Chemistry, University of Balochistan, Quetta, Pakistan.

\section{References}

[1] F. W. Mackison, R. S. Stricoff, and L. J. Partridge, , NIOSH/ OSHA-ccupational Health Guidelines for Chemical Hazards, DHHS (NIOSH), vol. 3, U.S. Government Printing Office, Washington, DC, USA, Publication No. 81-123, 1981.

[2] M. J. O'Neil, The Merck Index: An Encyclopedia of Chemicals, Drugs, and Biologicals, Merck \& Company, Whitehouse Station, NJ, USA, 13th edition, 2001.

[3] NIOSH, NIOSH Pocket Guide to Chemical Hazards \& Other Databases, DHHS (NIOSH) Publication No. 2001-145, U.S. Department of Health \& Human Services, Public Health Service, Center for Disease Control \& Prevention, Cincinnati, Ohio, USA, 2001.

[4] C. P. Richter, "The development and use of alpha-naphthyl thiourea (ANTU) as a rat poison," Journal of the American Medical Association, vol. 129, no. 14, pp. 927-931, 1945.

[5] International Agency for Research on Cancer (IARC), Monographs on the Evaluation of the Carcinogenic Risk of Chemicals to Man, 1972-Present, Multivolume Work, World Health Organization, IARC, Geneva, Switzerland, 1983.

[6] C. R. Worthing, The Pesticide Manual, (A World Compendium), The British Crop Protection Council, Croydon, England, 7th edition, 1983.

[7] S. Budavari, The Merck Index: An Encyclopedia of Chemicals, Drugs, and Biologicals, Merck \& Company, Rahway, NJ, USA, 11th edition, 1989.

[8] Department of Health and Senior Services, Hazardous Substance Fact Sheet Alpha-Naphthylthiourea, Department of Health and Senior Services, Trenton, NJ, USA, 2001.

[9] J. L. G. Mar, L. L. Martinez, P. L. L. de Alba, J. E. C. Duran, and V. C. Martin, "Optical fibre reflectance sensor coupled to a multisyringe flow injection system for preconcentration and determination of 1-naphthylamine in water samples," Analytica Chimica Acta, vol. 573-574, pp. 406412, 2006. 
[10] E. Bremanis and K. G. Bergner, "Detection of 1-naphthylthiourea (ANTU)," Pharmazeutische Zentralhalle Fur Deutschland, vol. 89, pp. 115-118, 1950.

[11] J. Vachek, "Color reactions of various sulfhydryl compounds and reducing sugars with sodium nitroprusside," Die Pharmazie, vol. 15, pp. 707-710, 1960.

[12] F. G. Sanchez and A. A. Gallardo, "Fluorimetric determination of the rodenticide ANTU in spiked wheat grain," Microchimca Acta, vol. 110, no. 4-6, pp. 161-166, 1993.

[13] M. R. Smyth and J. G. Osteryoung, "Determination of some thiourea-containing pesticides by pulse voltammetric methods of analysis," Analytical Chemistry, vol. 49, no. 14, pp. 23102314, 1977.

[14] V. Stara and M. Kopanica, "Adsorptive stripping voltammetric determination of thiourea and thiourea derivatives," Analytica Chimica Acta, vol. 159, pp. 105-110, 1984.

[15] T. G. Diaz, M. I. Acedo, A. M. de la Pena, M. S. Pena, and F. Salinas, "Determination of 1-naphthylamine and the related pesticides, naptalam and antu, in river-water by highperformance liquid chromatography. Application to the study of the degradation processes of naptalam," Analyst, vol. 119, no. 6, pp. 1151-1155, 1994.

[16] N. Wang and W. L. Budde, "Determination of carbamate, urea, and thiourea pesticides and herbicides in water," Analytical Chemistry, vol. 73, no. 5, pp. 997-1006, 2001.

[17] M. Maizels and W. L. Budde, "Exact mass measurements for confirmation of pesticides and herbicides determined by liquid chromatography/time-of-flight mass spectrometry," Analytical Chemistry, vol. 73, no. 22, pp. 5436-5440, 2001.

[18] C. J. Miles and H. Moye, "Postcolumn photolysis of pesticides for fluorometric determination by high-performance liquid chromatography," Analytical Chemistry, vol. 60, no. 3, pp. 220-226, 1988.

[19] J. A. M. Pulgarin, L. F. G. Bermejo, and J. A. R. Aranda, "Development of time-resolved chemiluminescence for the determination of Antu in river water, wheat, barley, and oat grain samples," Journal of Agricultural and Food Chemistry, vol. 53, no. 17, pp. 6609-6615, 2005.

[20] J. Ruzicka and E. H Hansen, Flow Injection Analysis, John Wiley \& Sons, New York, NY, USA, 2nd edition, 1988.

[21] Z. Marczenko, Spectrophotometric Determination of Elements, John Wiley \& Sons, New York, NY, USA, 1976.

[22] S. H. Yalkowsky, Y. He, and P. Jain, Handbook of Aqueous Solubility Data, CRC Press, Taylor \& Francis Group, New York, NY, USA, 2nd edition, 2010.

[23] S. S. M. Hassan, S. A. M. Marzouk, and H. E. M. Sayour, "Selective potentiometric determination of nitrite ion using a novel (4-sulphophenylazo-)1-naphthylamine membrane sensor," Talanta, vol. 59, no. 6, pp. 1237-1244, 2003. 

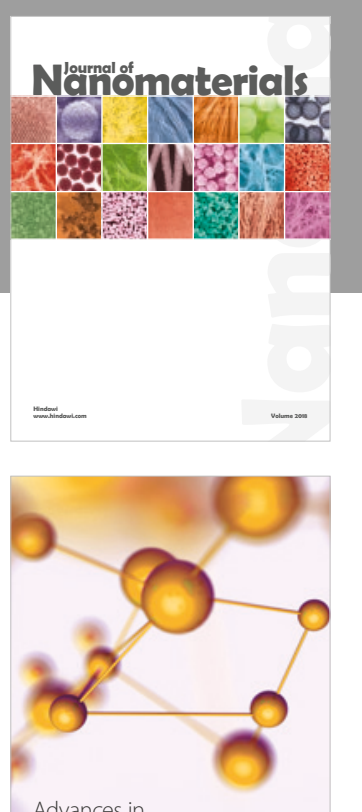

Physical Chemistry
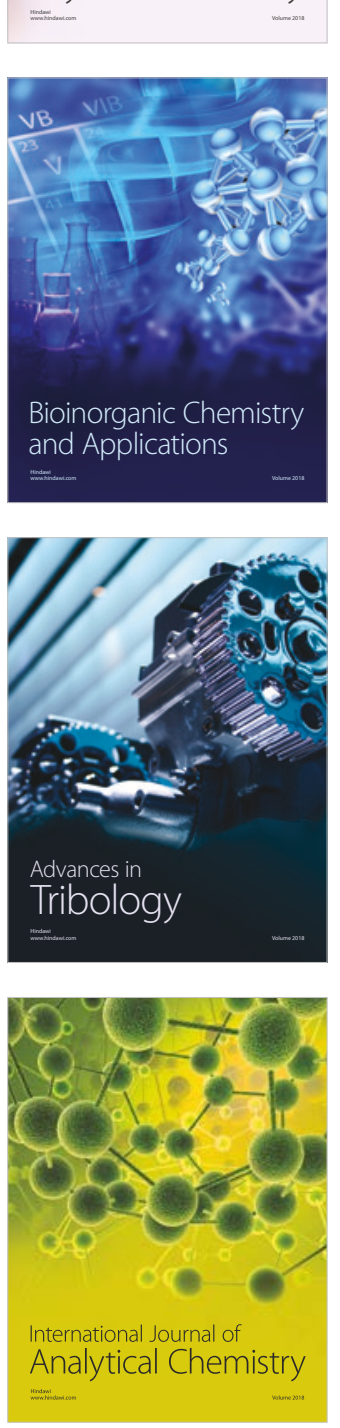

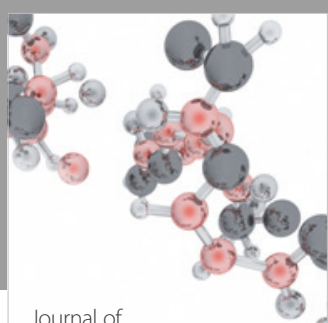

Analytical Methods

in Chemistry

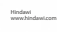

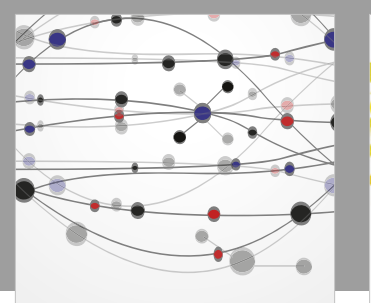

The Scientific World Journal

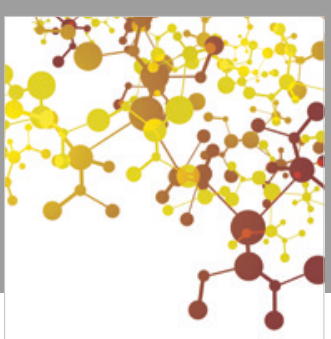

Journal of

Applied Chemistry
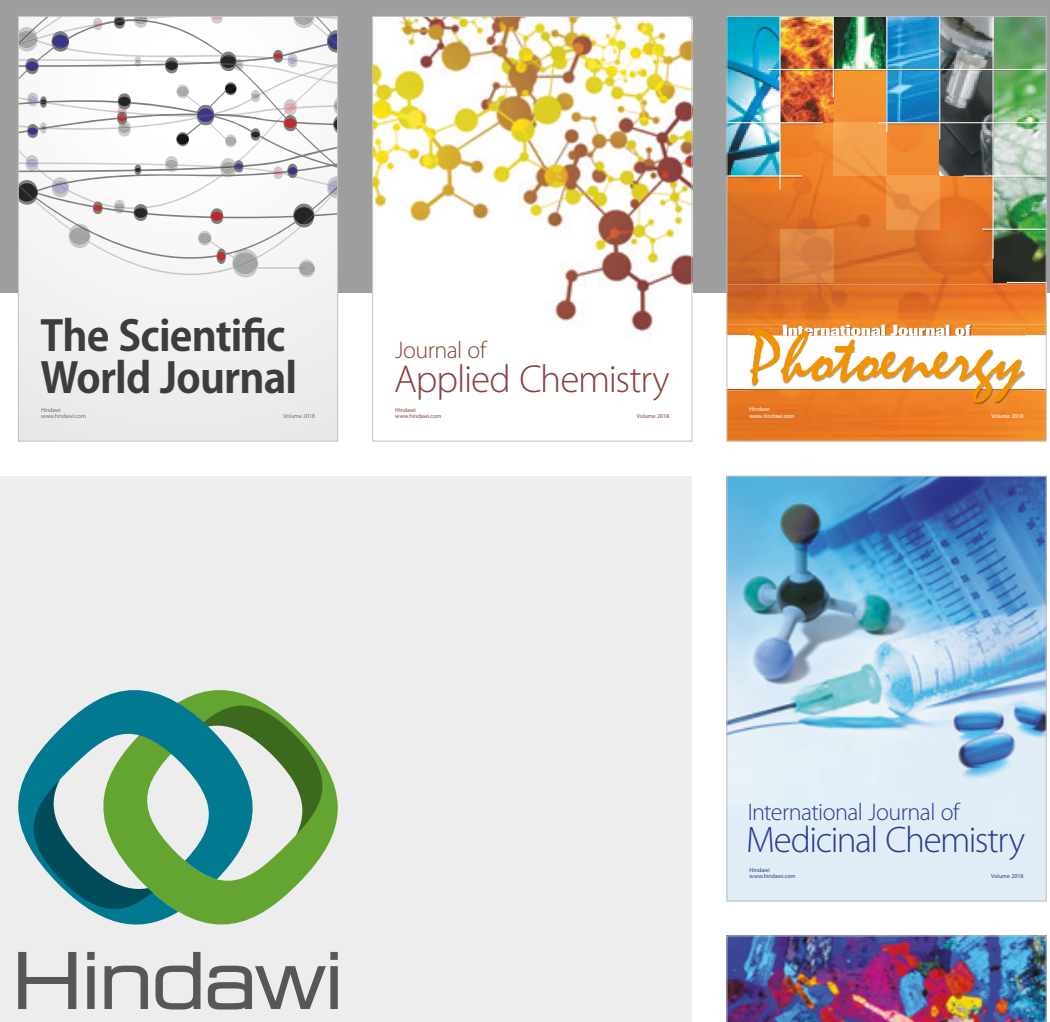

Submit your manuscripts at

www.hindawi.com
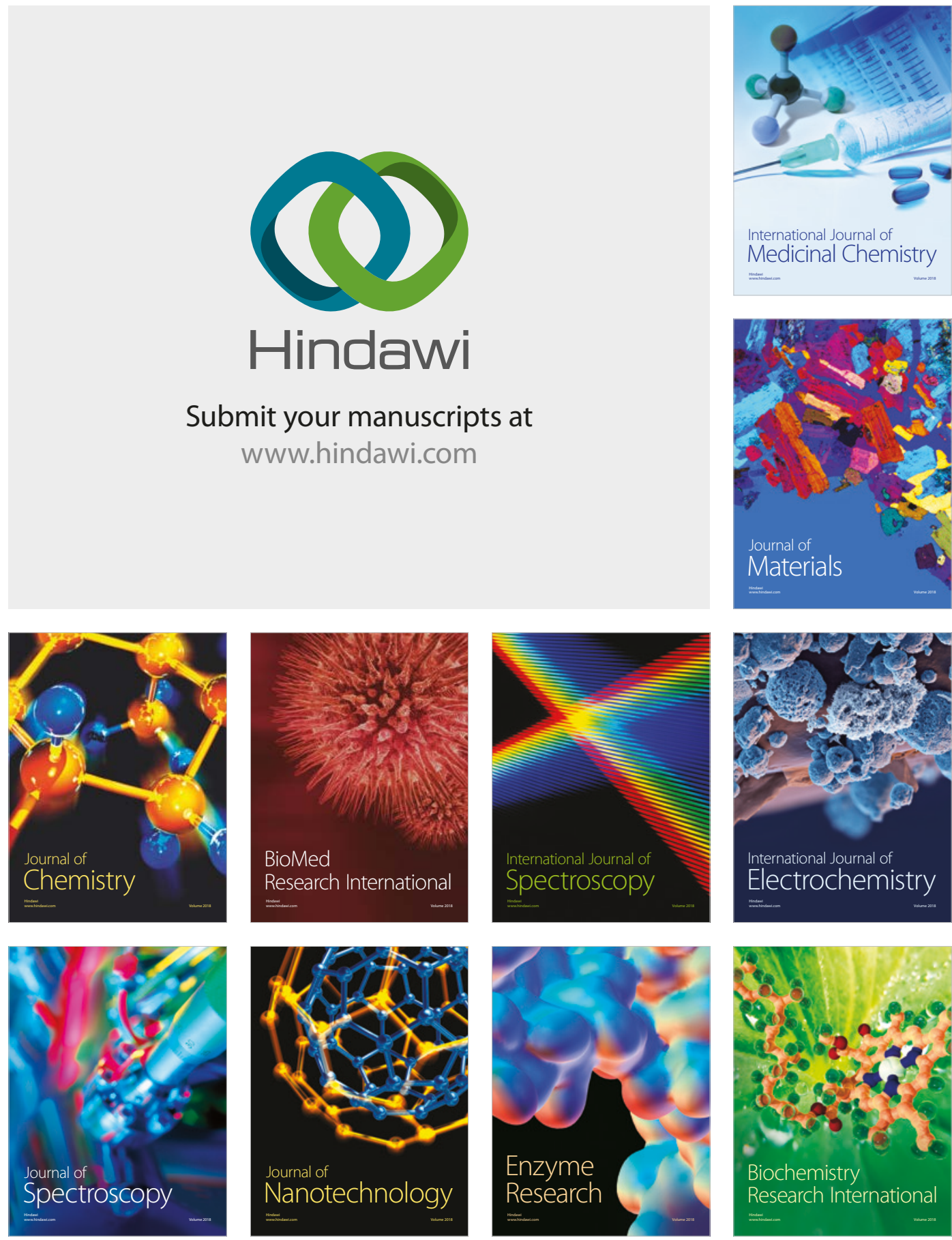
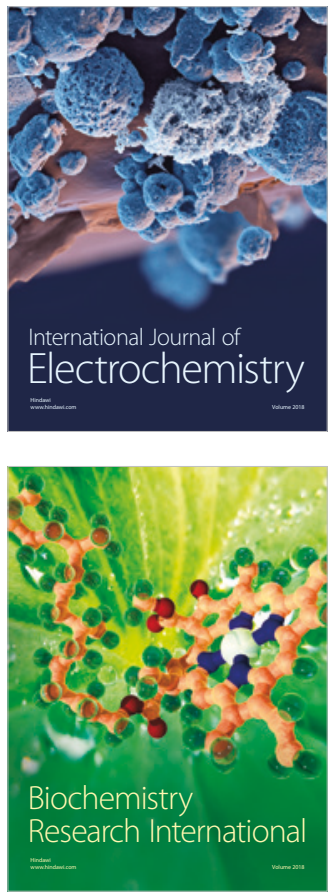